\title{
Patient blood management: the solution to a double-edged sword?
}

\author{
YE Chee ${ }^{1,2,3,4}$ *, MB, BS, FHKAM (Anaesthesiology), CS Lau ${ }^{5,6}, \mathrm{MB}, \mathrm{ChB}$, FHKAM (Medicine) \\ ${ }^{1}$ Chief of Service, Department of Anaesthesia, Queen Mary Hospital \\ ${ }^{2}$ Vice President, Society of Anaesthetists in Hong Kong \\ ${ }^{3}$ Honorary Clinical Associate Professor, The University of Hong Kong, Hong Kong \\ ${ }^{4}$ Honorary Clinical Associate Professor, The Chinese University of Hong Kong, Hong Kong \\ ${ }^{5}$ Chair and Daniel CK Yu Professor in Rheumatology and Clinical Immunology, Department of Medicine, The University of Hong Kong, \\ Hong Kong \\ ${ }^{6}$ President, Hong Kong Academy of Medicine, Hong Kong \\ * Corresponding author: cye254@ha.org.hk
}

Hong Kong Med J 2020;26:280-2

https://doi.org/10.12809/hkmj205104

In 1818, British obstetrician James Blundell successfully treated a patient diagnosed with postpartum haemorrhage with allogeneic blood transfusion. Transfusion medicine has since come a long way. The discovery of ABO blood groups in 1900 and Rh factor in 1939 by the Austrian immunologist Karl Landsteiner, ${ }^{1}$ the use of anticoagulants to preserve donor blood, and the implementation of donor blood screening tests for HBV (1970), HIV (1984), and HCV (1990), were all important milestones that helped to mitigate risks and enhance safety in blood transfusion practice. Today, allogeneic blood transfusion has become a mainstay in the treatment of anaemia ${ }^{2}$ and is among the most frequently prescribed life-saving therapies. ${ }^{3,4}$ Paradoxically, growing evidence shows that blood transfusion is associated with adverse patient outcomes. ${ }^{5}$ Blood transfusion is linked to increased infections and sepsis, length of hospital stay, and all-cause mortality. ${ }^{5,6}$

The sustainability of the donor blood supply is also at stake. Globally, the population aged $\geq 65$ years is growing faster than all other age-groups, and the ratio is expected to increase from the current 1 in $11(9 \%)$ to 1 in $6(16 \%)$ by $2050 .^{7,8}$ Because patients aged $\geq 65$ years receive at least $50 \%$ of all blood transfusions, ${ }^{9,10}$ this 'inverted pyramid' in population growth means an imminent threat to the long-term blood supply. Critical shortages of allogeneic blood supply will soon ensue should the donation pattern and transfusion practices remain unchanged. ${ }^{9}$ The outcome impact and scarcity of supply call for a comprehensive approach in blood transfusion practice.

The term 'patient blood management' (PBM) was first coined by an Australian haematologist, Professor James Isbister, in 2005 to advocate a shift in transfusion practice from a blood product focus to a patient-centred one. ${ }^{11}$ An observational study conducted by the Austrian group on perioperative blood use showed high predictability of preoperative anaemia, volume of perioperative blood loss, and transfusion threshold for allogeneic blood transfusion, ${ }^{12}$ which laid the groundwork for PBM to be built on. Goodnough et al took the initiative further by rationalising PBM interventions into three main pillars ${ }^{13,14}$ :

1. detect and manage anaemia sufficiently early before major elective surgery;

2. exhaust all means to minimise iatrogenic blood loss; and

3. optimise anaemia tolerance to accommodate restrictive transfusion trigger.

Thus, PBM emerged as a multimodal, multi-disciplinary approach using evidence-based interventions to preserve or optimise patients' red cell mass and to avoid allogeneic blood transfusion. It aims to ensure patient safety and improve clinical outcomes. The originally intended use of PBM was to target perioperative blood use in surgical patients. Over the past few years, PBM has been extended to include nonsurgical indications. ${ }^{15}$ The initiative was formally endorsed at the World Health Assembly in $2010 .^{16}$

In the past decade, support for PBM has grown in the practice of transfusion medicine, and much effort has been invested clinically to implement PBM. While PBM is most effective as an integrated part of a multidisciplinary clinical pathway, ${ }^{17}$ often only a single intervention or a pillar of PBM is implemented by an individual department in a piecemeal manner. Few institutions run PBM as a comprehensive hospital-wide programme that encompasses all measures guided by a transfusion algorithm. ${ }^{18}$ Barriers to wider implementation of PBM include clinicians' resistance to change, lack of engagement of health authorities and policy makers, lack of resources, difficulties in translating evidencebased guidelines into feasible clinical practice, and an effective outcome audit. ${ }^{17-19}$ In 2008, the Western Australia Department of Health initiated a 5-year project to implement a health system-wide PBM 
programme that involved re-engineering of clinical processes and change management at all levels of the healthcare organisation. The successful initiative led to significant reductions in blood transfusion, hospital acquired infections, in-hospital mortality, hospital length of stay, and readmission rate. The reduction in transfusion alone was translated into a saving of over AU\$18 million from product procurement and AU\$80 million from activity-based savings. ${ }^{17,18}$ The initiative showcased the successful implementation of a PBM programme that required engagement and participation of regulatory bodies and health authorities in addition to clinical leadership, fund allocation, and technology support. ${ }^{18,20,21}$ Of course, the economic burden of blood transfusion and hence the cost savings resulted give added value to a well-run PBM programme. ${ }^{18,20-22}$

The 2018 Frankfurt Consensus Conference made 10 clinical and 12 research recommendations on preoperative anaemia management, transfusion thresholds in adults, and implementation of PBM programmes. ${ }^{23}$ The panel found a paucity of strong evidence to answer many questions related to the three pillars in PBM and these deficiencies in the literature support the need for further research. The panel also highlighted the lack of agreement on the haemoglobin level for the diagnosis of preoperative anaemia, challenged the long-standing definition by the World Health Organization that was derived in the 1960s from small and low-quality trials, and emphasised the importance of an evidence-based, internationally accepted haemoglobin value for preoperative anaemia diagnosis in order to make future studies comparable.

The Hong Kong Red Cross Blood Transfusion Service is the only public institution providing blood to all public and private hospitals in Hong Kong, with $>90 \%$ used within HA hospitals. Local non-remunerated voluntary donors are the sole suppliers of blood in Hong Kong. Procurement of blood from overseas is not a standard practice except for patients of non-Chinese ethnic background with unusual red cell antibodies receiving treatment in Hong Kong. The cost of collecting a unit of whole blood was previously estimated to be approximately $\mathrm{HK} \$ 1000$, but this has increased to around HK\$1200 in the past 2 years owing to increased overhead costs. An ageing population together with the threats from emerging infectious diseases have prompted clinicians and hospital administrators in Hong Kong to adopt a full range of PBM interventions.

This themed issue of Hong Kong Medical Journal features the Recommendations on Implementation of Patient Blood Management by a group of local experts from the Hong Kong Society of Clinical Blood Management, ${ }^{24}$ highlighting the challenges in the broader implementation of PBM in Hong Kong and ways to overcome these. We offer this special edition to our readers as evidence of our commitment to PBM and its value to the patients served.

\section{Author contributions}

All authors contributed to the editorial, approved the final version for publication, and take responsibility for its accuracy and integrity.

\section{Acknowledgement}

We thank Dr Cheuk-kwong Lee and Dr Rock Leung for their valuable inputs to this editorial.

\section{Conflict of interest}

The authors have disclosed no conflicts of interest.

\section{References}

1. Farhud DD, Yeganeh MZ. A brief history of human blood groups. Iran J Public Health 2013;42:1-6.

2. Partridge J, Harari D, Gossage J, Dhesi J. Anaemia in the older surgical patient: a review of prevalence, causes, implications and management. J R Soc Med 2013;106:26977.

3. Trentino KM, Farmer SL, Swain SG, et al. Increased hospital costs associated with red blood cell transfusion. Transfusion 2015;55:1082-9.

4. Villanueva C, Colomo A, Bosch A, et al. Transfusion strategies for acute upper gastrointestinal bleeding. N Engl J Med 2013;368:11-21.

5. Isbister JP, Shander A, Spahn DR, et al. Adverse blood transfusion outcomes: establishing causation. Transfus Med Rev 2011;25:89-101.

6. Bernard AC, Davenport DL, Chang PK, et al. Intraoperative transfusion of $1 \mathrm{U}$ to $2 \mathrm{U}$ packed red blood cells is associated with increased 30-day mortality, surgical-site infection, pneumonia, and sepsis in general surgery patients. J Am Coll Surg 2009;208:931-7.e1-2.

7. Ali A, Auvinen M, Rautonen J. The aging population poses a global challenge for blood services. Transfusion 2010;50:584-8.

8. United Nations. World Population Ageing 2019. Available from: https://www.un.org/en/development/ desa / population / publications / pdf/ageing/ WorldPopulationAgeing2019-Report.pdf. Accessed 5 Aug 2020.

9. Greinacher A, Fendrich K, Brze3nska R, Kiefel V, Hoffmann W. Implications of demographics on future blood supply: a population-based cross-sectional study. Transfusion 2011;51:702-9.

10. Cobain TJ, Vamvakas EC, Wells A, Titlestad K. A survey of the demographics of blood use. Transfus Med 2007;17:115.

11. Isbister J. Why should health professionals be concerned about blood management and blood conservation? Updates Blood Conserv Transfus Alternat 2005;2:3-7.

12. Gombotz H, Rehak PH, Shander A, Hofmann A. Blood use in elective surgery: the Austrian benchmark study. Transfusion 2007;47:1468-80.

13. Goodnough LT, Shander A, Brecher ME. Transfusion medicine: looking to the future. Lancet 2003;361:161-9.

14. Shander A, Isbister J, Gombotz H. Patient blood management: the global view Transfusion 2016;56 Suppl 
1:S94-102.

15. Franchini M, Marano G, Veropalumbo E, et al. Patient blood management: a revolutionary approach to transfusion medicine. Blood Transfus 2019;17:191-5.

16. The Sixty-third World Health Assembly. Availability, safety and quality of blood products. 2010. Available from: http:// apps.who.int/gb/ebwha/pdf_files/WHA63/A63_R12-en. pdf. Accessed 27 Oct 2017.

17. Farmer SL, Towler SC, Leahy MF, Hofmann A. Drivers for change: Western Australia Patient Blood Management Program (WA PBMP), World Health Assembly (WHA) and Advisory Committee on Blood Safety and Availability (ACBSA). Best Pract Res Clin Anaesthesiol 2013;27:43-58.

18. Leahy MF, Hofmann A, Towler S, et al. Improved outcomes and reduced costs associated with a health-system-wide patient blood management program: a retrospective observational study in four major adult tertiary-care hospitals. Transfusion 2017;57:1347-58.

19. Goodnough LT. Blood management: transfusion medicine comes of age. Lancet 2013;381:1791-2.
20. National Institute for Health and Care Excellence (NICE). Costing statement: blood transfusion. Implementing the NICE guideline on blood transfusion (NG24). November 2015. Available from: https://www.nice.org.uk/guidance/ ng24. Accessed 5 Aug 2020.

21. American Society of Hematology. Choosing wisely. An initiative of the ABIM Foundation. 2018. Available from: https://www.choosingwisely.org/wp-content/ uploads/2018/02/Blood-Transfusions-For-Anemia-InThe-Hospital-ASH.pdf. Accessed 5 Aug 2020.

22. Abraham I, Sun D. The cost of blood transfusion in Western Europe as estimated from six studies. Transfusion 2012;52:1983-8.

23. Mueller MM, Remoortel HV, Meybohm P, et al. Patient blood management: recommendations from the 2018 Frankfurt Consensus Conference. JAMA 2019;321:983-97.

24. Chow YF, Cheng BC, Cheng HK, et al. Hong Kong Society of Clinical Blood Management recommendations for implementation of patient blood management. Hong Kong Med J 2020;26:331-8. 